\title{
INTEGRAÇÃO DOS PROFISSIONAIS DE INFORMAÇÃO: O futuro em sinergia $\left.{ }^{*}\right)$
}

\author{
Patrícia Zeni Marchiori \\ Márcia R. L. Pacheco
}

\begin{abstract}
Resumo
Deve-se identificar o campo que é composto de profissões/ocupações que trabalham com a informação. Esse campo, por suas características, não prevê monopólios, deixando espaços para uma concorrência aberta. Pode-se afirmar que vários profissionais, entre eles o bibliotecário e o arquivista, compartilham do mesmo "estrato/núcleo" profissional, caracterizado pela prestação de serviços de informação. Esses profissionais possuem objetivos comuns, pois suas atividades procuram identificar o "tipo" de informação desejada pelos clientes, a "natureza" dessa demanda de informação e a identificação de "como" modelos e/ou serviços de informação podem ser operados. As profissões vinculadas à área de informação devem buscar, por categoria, estruturar-se de forma associativa em uma entidade de tipo "guarda chuva".
\end{abstract}

\section{Palavras-Chave}

Profissionais da informação - Bibliotecários Arquivistas - Movimento Associativo

\section{INTRODUÇÃO}

Podemos afirmar que a sociedade contemporânea vem apresentando modificações sensíveis na aquisição, no processamento e no acesso a informações, com base na proliferação, qualidade e vulgarização dos recursos tecnológicos. Essa é uma realidade nos países desenvolvidos, cuja preocupação, hoje, é a definição de padrões de troca de informações, a utilização dos recursos computacionais e de telemática, bem como a modificação dos mercados de trabalho no que diz respeito aos perfis dos profissionais que neles atuam.

\footnotetext{
(*) Trabalho apresentado na Sessão de Comunicações do 10. Congresso Brasileiro de Arquivologia. São Paulo, 27 de nov. a 02 de dez. de 1994 sob o título O Campo de atividades de informação e suas interfaces.
}

Desta forma, as distintas concepções de informação, o crescente processo de autonomia da esfera informativa e a progressiva expansão de atividades e mercados de informação, ocasionou o surgimento de termos relativamente novos, tais como: setor de informação/ information work force (KLING, 1990), knowledge work (KNIGHT, citado por KLING, 1990), campo de atividades de informação (MARCHIORI, 1992), entre outros, que pretendem identificar um setor ou campo que é composto de profissões/ocupações nos quais pessoas devotam o seu tempo e direcionam grande parte do seu trabalho para registrar, processar, armazenar, pesquisar, disseminar ou comunicar informações.

O crescimento e o reconhecimento desse campo de atividades de informação (CAI), tem provocado estudos de tipologias industriais, ocupacionais e de recursos humanos relacionadas 
com o setor informativo, tais como os trabalhos de VITRO (1983) e PORAT e RUBIN (citados por KLING, 1990).

Não se pretende aqui, discutir sobre a distinção entre ocupação e profissão. Contudo, poder-se-ia destacar o comentário de DEWEESE, citado por ASHEIM (1979), o qual diz que a ocupação/profisssão de um indivíduo tem progressivamente substituído e revelado mais sobre a sua posição social do que qualquer outro atributo (à exceção talvez da raça) tal como: religião, nome de família, filiação partidária, entre outros.

De qualquer maneira, a existência de uma profissão está atrelada ao uso de um conhecimento que é passível de ensino, aprendizagem e socialmente útil (ASHEIM, 1979, p. 228). No entanto, o perfil do profissional não é determinado apenas pelo volume de conhecimentos institucionalizados, mas também, pelos "capitais" (ou seja, hábitos, atitudes, estrutura sócio-cultural, e outras habilidades/ vocações) agregados pelo indivíduo em sua trajetória de vida.

\section{A TIPOLOGIA DAS PROFISSÕES DE INFORMAÇÃO E SUAS INTERFACES}

As universidades são as instituições encarregadas dos programas de treinamento, caracterizando-se com as esferas de legitimação dos 'monopólios de competência, que, em conjunto com as demais condições acima, caracterizam um processo dinâmico “... onde os profissionais 'lutam' visando a conquista e garantia de privilégios para a sua profissão (MARINHO, 1986, p.92).

No campo de atividades de informações, existe por um lado, uma fragmentação dos conhecimentos institucionalizados (no caso dos currículos das universidades) que promovem perfis profissionais diferenciados, mas que, se analisados como um todo, complementam-se e favorecem a identificação do próprio campo.

O campo de atividades de informação, dadas as suas características, não prevê monopólios distintos, deixando espaço para uma concorrência aberta em que os agentes legitimados devem ser cada vez mais competentes, flexíveis, criativos polivalentes (BOWES, 1991). Rob KLING, em seu estudo sobre a estratificação ocupacional e o mercado de trabalho no Setor Informativo NorteAmericano, adaptou a tipologia de caracterização dos trabalhos de informação de PORAT, dividindo os trabalhos com informação em cinco estratos: profissões; semiprofissões; pessoal de supervisão e vendas; pessoal ligado a serviços de escritório; operários encarregados de máquinas de processamento de informações (KLING, 1990, p.86-88).

Tal tipologia, estruturada a partir do censo Norte-Americano, incluiu ocupações como: contadores, advogados, médicos, cientistas sociais, bibliotecários, arquivistas, jornalistas, operadores de computadores, secretárias, datilógrafas, vendedores, entre outros, como profissionais atuantes na prestação de serviços e/ou atividades de informação. Tanto na classificação de PORAT (KLING, 1990), como na de KLING (1990), a Biblioteconomia, a Arquivística e a Museologia são consideradas como semiprofissões. O Jornalismo aparece para o primeiro autor como atividade ligada a serviços de escritório e, para o segundo, como semiprofissão (englobado na categoria de 'outros profissionais técnicos') enquanto que Informática aparece como semiprofissão para PORAT, dividindo-se para KLING, em função da especialidade, como profissão (analista de sistemas); semiprofissão (especialistas em computação) e ainda como pessoal ligado a operação e manutenção de computadores.

O fato é que, embora fragmentadas em seus corpos teóricos e alocados em tipologias nem sempre consistentes, pode-se dizer que os jornalistas, editores, tradutores, pesquisadores de marketing e de mercado, publicitários, arquivistas, museólogos, historiadores, bibliotecários, informativos e consultores em geral, compartilham do mesmo "core" ou "estrato/núcleo" profissional, caracterizado pela prestação de serviços de informação, cujas atividades não são conflitantes, mas intercomplementares, embora possam superporse em função das necessidades de mercado (JUCQUOIS-DELPIERRE, 1994, P. 6).

Esses profissionais têm objetivos comuns, uma vez que em suas atividades procuram:

a) Identificar o "tipo" de informação desejado pelos usuários/clientes;

b) Identificar a "natureza" dessa demanda de informação, incrementando modelos de serviços e/ou produtos (produção, coleta, Inf.Inf., Londrina, v.2, n.2, p.55-58, jul./dez. 1997 
análise, tratamento, organização, etc.) que venham a resolver o "problema" de informação do usuário/cliente a curto, médio ou longo prazo;

c) Identificar "como" esses modelos devem ser operados de modo a resultar em serviços de qualidade, racionalizando investimentos e incrementando os benefícios.

\section{OS PROFISSIONAIS DA INFORMAÇÃO E SUA POSSÍVEL INTEGRAÇÃO ASSOCIATIVA}

Historicamente, cada uma dessas profissões de informação estruturou (ou vem estruturando) isoladamente seus movimentos associativos em busca de reconhecimento legal e trabalhista sem, contudo, obterem resultados positivos e consistentes, quer na proteção de seus "monopólios", quer na manutenção e expansão do mercado de trabalho com informação. O que se percebe é uma pulverização de esforços, com resultados muitas vezes desanimadores.

A configuração multidisciplinar do campo de atividades de informação, associa-se a considerações no que diz respeito a: 1) queda progressiva das fronteiras entre as profissões de informação; 2) exigências do mercado quanto ao perfil do profissional da informação e as novas ocupações que vêm surgindo para atender a essa demanda; 3) a globalização da economia (no caso do Brasil, a instalação do Mercosul em 1995), que proporcionará oportunidades de intercâmbios profissionais os mais diversos.

Diferentes posturas/ações podem ser assumidas diante deste quadro. $\mathrm{Na}$ opinião das autoras, o impacto negativo decorrente de tais mudanças poderia ser minimizado, caso houvesse uma conjunção de interesses. Mesmo que as estruturas curriculares das instituições encarregadas da formação profissional permanecessem inalteradas, nada impede que as categorias reunam esforços associativos e representativos sob a estrutura de uma entidade "guarda-chuva", como fazem os engenheiros, arquitetos e agrônomos em seus CREAs. Assim, respeitadas as características de cada profíssão envolvida, haveria um trabalho em sinergia, podendo tal categoria (profissionais da informação) obter respaldos políticos e sociais muito mais significativos do que envidando esforços individuais.

\section{REFERÊNCIAS BIBLIOGRÁFICAS}

ASHEIM, Lester. Librarian as professionals. Library Trends, Chicago, v.7, n.8, p.225-257, Winter 1979.

BOWES, Roger. Expanding the information horizon: alterantives carees for information professional. Aslib Proceedings, Great Britain, v.43, n.9, p.217-275, Sept. 1991.

JUCQUOIS-DELPIERRE, Monique. Successful information training linking different information professions. In: FID/ EDUCATION AND TRAINING SEMINAR, 1994, Tókio. Anais. Copenhagen, 1994. p.47.

KLING, Bob. More information, better jobs?: occupational stratification and labor-market segmentation in United States' information labor force. The Information Society, v.7, n.2, p.77-107, June 1990.

MARCHIORI, Patrícia Zeni. A posição relativa dos profissionais de Biblioteconomia, Jornalismo e Informática no Campo de Atividades de Informação no Município de Curitiba: análise da formação acadêmica na Universidade Federal do Paraná, em conjunto com indicadores sociológicos. Rio de Janeiro, 1992. 383f. Dissertação (Mestrado em Ciência da Informação) - Escola de Comunicação, Universidade Federal do Rio de Janeiro. 


\section{Patrícia Zeni Marchiori}

Professora Assistente I / Departamento de Biblioteconomia / Universidade Federal do Paraná, Mestre em Ciência da Informação (CNPq/IBICY/UFRJ/ECO)

\section{Márcia R. L. Pacheco}

Consultora Idea Consultores Associados S/C Ltda. Especialista em Sistemas Automatizados em Informação (PUC/Campinas)

\section{Title}

Integration of Professionals of Information: the future in synergy.

\section{Abstract}

It is necessary to identify the field composed bu professions/occupations that deal with information. Such field, due to its characteristics, does not foresee monopoly, leaving room for an open competitiveness. It is possible to say that divers professionals, amongst wich are the librarians and the archivists, share the same professional "stratus/nucleous", characterized by information service. These professionals have common goals, since their activities try to identify the "tipe" of information desired by their clients, the "nature" of such demand of information, and the identification of "how" models and/or information services may be operated. The professions linked to the information area should, each category, try to become structured, in an associative way, to an "umbrella-type" entity.

\section{Keyworlds}

Professionals of Information - Librarians - Archivists - Associative Movement 